\title{
Practical conduct of open heart procedures for congenital heart lesions
}

\author{
T. K. Susheel Kumar \\ Department of Congenital Cardiothoracic Surgery, NYU Langone Health, New York, NY, USA \\ Correspondence to: T. K. Susheel Kumar, MD. Associate Professor, Department of Congenital Cardiothoracic Surgery, NYU Langone Health, New \\ York, NY 10016, USA. Email: tksusheel.kumar@nyulangone.org.
}

\begin{abstract}
Open heart surgery on infants with congenital heart lesions can be challenging not only in terms of the surgical procedure itself but also for setting up ideal conditions for safe and smooth conduct of cardiopulmonary bypass (CPB). The surgeon has to deal with a variety of lesions in a subgroup of patients who offer little room for any error. Familiarity with the principles of $\mathrm{CPB}$, check lists and protocols go a long way in improving outcome in this critical group of patients.
\end{abstract}

Keywords: Cardiopulmonary bypass (CPB); congenital; children

Submitted Oct 14, 2019. Accepted for publication Nov 20, 2019.

doi: $10.21037 /$ jtd.2019.11.80

View this article at: http://dx.doi.org/10.21037/jtd.2019.11.80

Surgical procedures for congenital heart lesions can often be challenging not only in terms of the actual procedure itself but also for setting up the right cardiopulmonary bypass (CPB) conditions for the safe conduct of the procedure. The institution, conduct and termination of $\mathrm{CPB}$ have been compared to piloting of an airplane, both requiring constant attention and monitoring (1). The airline industry has inculcated check lists for all key stages of operation making air travel one of the safest modes of modern travel. Similar protocols and checklists for the surgeons, perfusionists and other members of the team could go a long way in making $\mathrm{CPB}$ safe for patients especially in the pediatric age group suffering from congenital heart lesions. Safe conduct of $\mathrm{CPB}$ is crucial to successful outcome in this subgroup of patients who often have a very narrow margin of safety. The following is a broad overview of the various steps of open heart surgery without going into the details of every step. The intention is to help the operator frame a plan for the safe conduct of open heart procedures for congenital heart lesions. Check lists have been added for keys steps of CPB.

\section{History}

The concept of CPB and open heart surgery underwent a revolution when Dr. John H. Gibbon Jr did the first successful intracardiac repair of an atrial septal defect using a heart lung machine in May, 1953 (2). Over the next couple of decades improvements in the practice of cardiac surgery, myocardial protection, technology and understanding of pathophysiology associated with CPB significantly improved the safety and outcome of open heart procedures on CPB. Although there were sporadic reports of accidents on CPB it was not until Stoney et al published their report in 1980 that the frequency of adverse events occurring during CPB came to light (3). This led to the adoption of safer techniques and practices. However, the rate of adverse events still continues to be significant both in the adult and pediatric population $(4,5)$.

\section{Stages of an open heart procedure}

An open heart operation with intracardiac procedure typically comprises of 5 essential stages. This is true no matter how complicated the operation is:

(I) connection of patient to the external CPB machine via arterial and venous cannulation;

(II) functional separation of the heart from the circulatory system achieved by application of aortic cross clamp and safe and effective cardiac arrest;

(III) performance of intracardiac procedure; 
(IV) reconnection of the heart to the circulatory system achieved by removal of aortic cross clamp following deairing of heart chambers;

(V) separation of the patient from external CPB machine via arterial and venous decannulation;

Not every open heart procedure requires cessation of heart activity for some duration (i.e., stage 2 and stage 4 ) as for example pulmonary valve replacement can be entirely done on beating heart. Each stage consists of important steps that should be performed sequentially for a successful outcome (see Figure 1 and Table 1).

The conduct of safe CPB involves personnel from different disciplines. The importance of functioning together as a team during conduction of CPB cannot be overstressed. There are extensive checklists and practice guidelines for perfusionists operating the pump (6). Similarly every surgeon should have mental check lists during the performance of critical stages of the operation. It is important to realize that although there is more than one way of performing a particular step, consistency of practice is paramount for improving safety in the operating room. This also makes communication easier between the various members of the team.

\section{Brief review of CPB strategies}

A brief mention of the different strategies of venting and myocardial management on CPB is made before enumerating the various steps and check lists of open heart procedure.

\section{Venting of heart}

Following institution of $\mathrm{CPB}$, the right and left heart chambers continue to receive blood.

The various sources of blood flow to the heart on CPB are as follows.

\section{Right heart}

(I) Systemic venous return around the cannulae;

(II) coronary sinus drainage. This is blood without the aorta cross clamped and cardioplegia intermittently when the clamp is on;

(III) left superior vena cava (SVC);

(IV) pulmonary collateral return retrograde across the pulmonary valve especially if the valve is incompetent.

\section{Left heart}

(I) Bronchial/Thebesian veins. This return is influenced by mean arterial pressure and presence of chronic lung infections/ cyanotic congenital heart disease (7);

(II) blood from the right heart across the pulmonary circuit;

(III) unusual sources:

* Systemic pulmonary connections like patent ductus arteriosus (PDA) and Blalock Taussig Thomas shunt;

* Septal defects like atrial septal defect (ASD) and ventricular septal defect (VSD);

- Anomalous systemic venous drainage like left SVC;

* Aortic regurgitation (AR) (preexisting/surgical manipulation).

Venting of the heart on CPB is essential to prevent distension that could result in myocardial stretch damage and pulmonary edema. Improper venting of the left heart results in:

(I) distension of the heart. There is a general consensus that the immature myocardium of neonates and infants is more vulnerable to stretch injury resulting from over distension of the heart (8);

(II) pulmonary edema. It is important to realize that pulmonary edema can happen without cardiac distension as for example following ligation of vertical vein without opening the common venous chamber in infradiaphragmatic total anomalous pulmonary venous connection (TAPVR). This can manifest as pump lung postoperatively.

Left ventricle (LV) distension occurs when it is unable to handle the load that is delivered to it. It happens most commonly at the following points during open heart surgery (9).

(I) At institution of CPB (cooling and hypocalcaemia);

(II) Ventricular fibrillation;

(III) Cross clamping of aorta;

(IV) Administration of cardioplegia.

$\mathrm{LV}$ distension is most easily detected by inspection and palpation (9). The left atrial (LA) vent serves the following purposes:

(I) prevents distension and mechanical damage from excessive stretching;

(II) prevents pulmonary venous hypertension and pulmonary edema;

(III) facilitates surgical exposure by decreasing blood in field for example during VSD closure; 


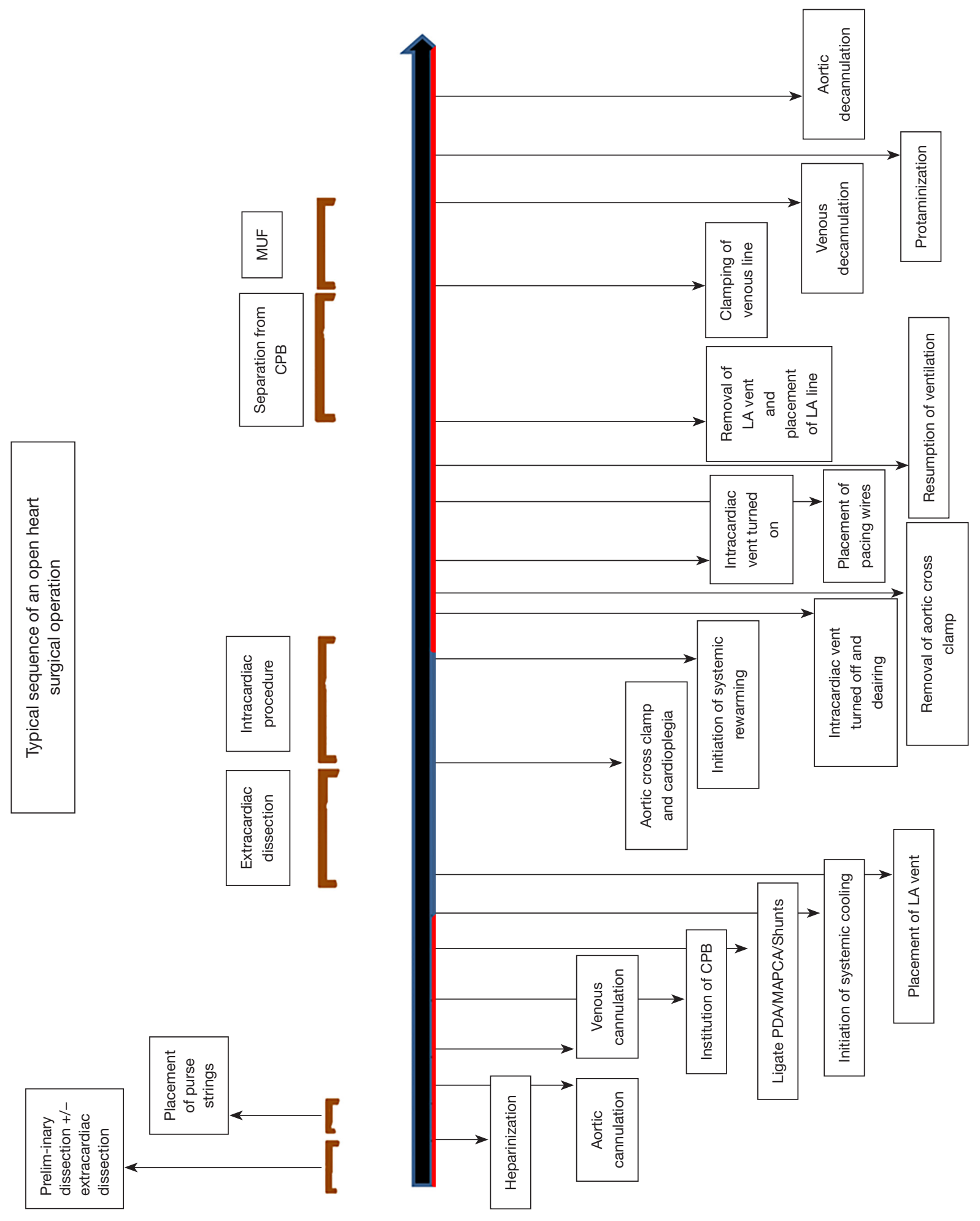

चี 
Table 1 Sequence of open heart surgery

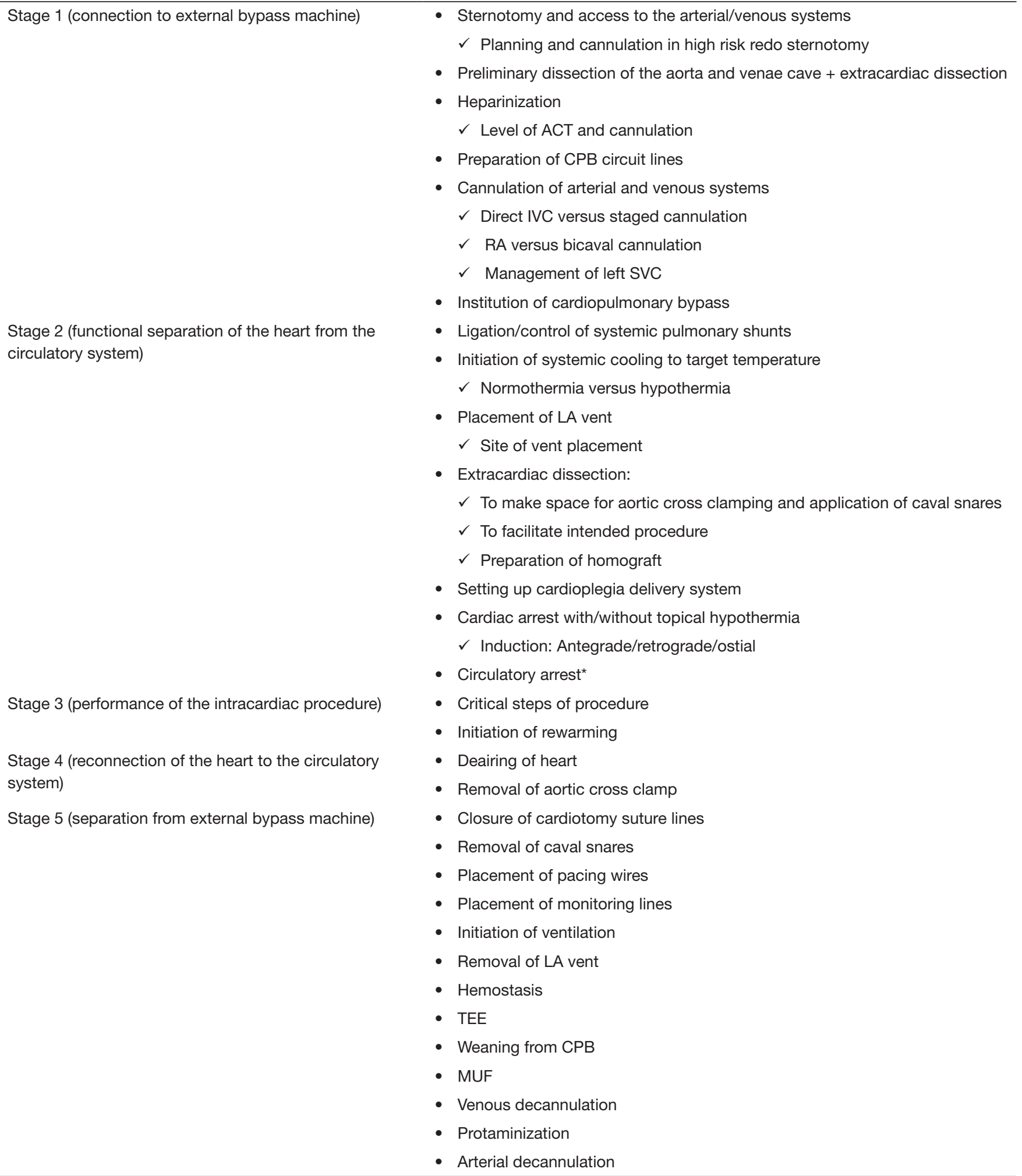

*, circulatory arrest not required in all cases. CPB, cardiopulmonary bypass; ACT, activated clotting time; SVC, superior vena cava; MUF, modified ultrafiltration; IVC, inferior vena cava; TEE, trans esophageal echocardiography; RA, right atrium; LA, left atrium. 
Table 2 Methods of venting left heart

\begin{tabular}{lll}
\hline Methods & Advantages & Disadvantages \\
\hline Ascending aorta (cardioplegia cannula) & $\bullet$ Simple & $\bullet$ Works only when aorta is cross clamped \\
& & $\bullet$ Does not work during administration of \\
antegrade cardioplegia
\end{tabular}

*, LA may also be directly cannulated. LA, left atrium; LV, left ventricle; RSPV, right superior pulmonary vein; AR, aortic regurgitation.

(IV) improves myocardial preservation;

(i) reduces myocardial rewarming and washout of cardioplegia;

(ii) decreases myocardial oxygen demand (decreases wall tension by reducing diameter of ventricle);

(iii) facilitates subendocardial perfusion (by decreasing $L V$ pressure).

Various methods of venting right heart include the following:

(I) Venous cannulae (SVC and IVC cannula);

(II) Separate right atrial (RA) cannula;

(III) Opening RA into pericardial sac;

(IV) LA vent via septal defect (ASD/VSD).

Methods of venting of the left heart are described in the Table 2.

\section{Purpose of aortic cross clamp}

Although cross clamp is mainly employed to enable an intracardiac procedure, it also serves other purposes:

(I) to prevent air embolism while the intracardiac procedure is being performed. E.g. Valve operation or closure of VSD;

(II) to provide a still field as for example coronary artery bypass grafting or RV outflow patch procedure when the incision is close to left anterior descending artery;

(III) to enable dissection as for example in infradiaphragmatic TAPVR lifting the heart to dissect out common chamber can cause AR and distend an already sick heart (10).

\section{Purpose of circulatory arrest}

Although employed chiefly for aortic arch operations, circulatory arrest is used in other situations.

(I) to provide a blood less field for example in repair of TAPVR;

(II) aortic surgery i.e., when working on the aorta beyond the cannulation site;

(III) intervention on IVC i.e., when working on the IVC below the cannulation site.

\section{Safe duration of circulatory arrest and temperature}

Presently there is not enough information to formulate an equation relating safe period of circulatory arrest to temperature. However almost all studies indicate that a period of less than 30 minutes is essentially safe and up to 45 minutes is acceptable at 18 degree $\mathrm{C}$ (11). At higher temperatures, the safe duration is unlikely to be beyond just a few minutes. Hence whenever circulatory arrest needs to be undertaken it is wise to cool all the way to deep hypothermia. Whenever short periods of circulatory arrest are required to enable dissection as for example in patients with excessive collateral flow, it is useful to cool at least to moderate hypothermia. This will allow short periods of safe circulatory arrest.

\section{Methods of myocardial management during CPB}

\section{Multiple dose cold cardioplegic arrest}

A number of cardioplegia solutions and techniques have been described (12). Both asanguinous and sanguineous 
Table 3 Techniques of cardioplegia administration

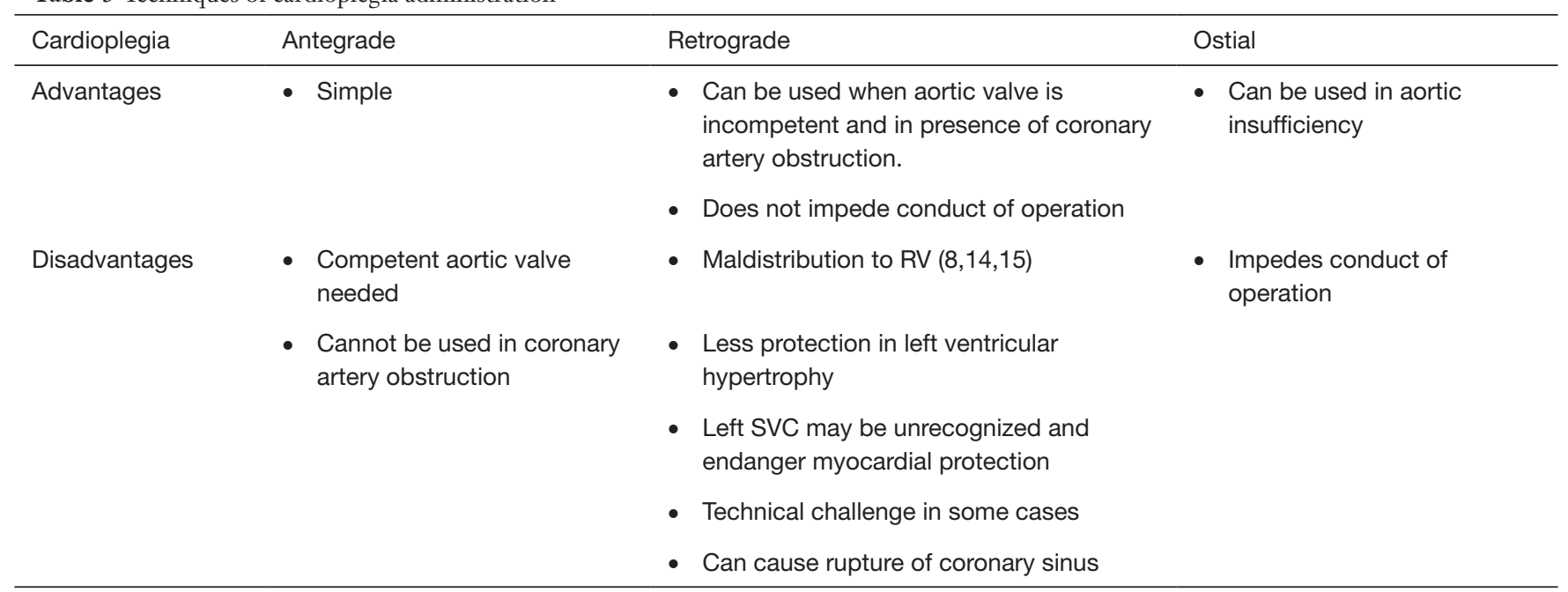

solutions have been used with good results. A safe and effective cardiac arrest is essential for good outcome. The choice of cardioplegia depends on the anatomy, the operation and the operator. When the cardioplegia needle is placed it is a good practice to confirm brisk bleeding from the cannula indicating full entry into the lumen of aorta. Topical hypothermia may be used when myocardial protection is critical and a long clamp time is anticipated although there is no clear data supporting its routine use at the moment (13).

The different techniques of cardioplegia administration are summarized in Table 3.

'Hot shot' (warm, hyperkalemic, enriched blood cardioplegia) just before removal of aortic cross clamp and warm cardioplegia induction may be useful in the very sick hearts (16). Warm blood induction is felt to be beneficial in dysfunctional hearts because arrest at 37 degree $\mathrm{C}$ without ischemia enhances metabolic repair by channeling the ATP production towards reparative processes. This technique is worth considering in those with energy depleted hearts such as patients with hemodynamic instability, severe cyanosis or heart failure $(8,17)$.

\section{Fibrillating heart}

Ventricular fibrillation with continuous coronary perfusion is a useful alternative to cardioplegic arrest for achieving a quiet field. Fibrillation can be induced and maintained by an electric current at normothermia. At moderate hypothermia, fibrillation can both be induced spontaneously or by electric current and can usually be maintained without continuous electric stimulation. Although there are some concerns about perfusion to the subendocardium especially in those with hypertrophy excellent results have been reported in adults (18). It is important to make sure that the heart is vented well during fibrillation. It is also a good idea to place an air vent in the ascending aorta.

Ventricular fibrillation reduces myocardial oxygen demand when compared to a working heart (19). This can be used to reduce the ischemic damage during the time interval between application of aortic cross clamp and initiation of retrograde cardioplegia (in retrograde cardioplegic induction).

\section{Empty beating heart}

This is another useful strategy that can be employed for certain operations like pulmonary valve replacement. Despite the evidence that the myocardial edema and altered pattern of coronary blood flow in an empty heart can cause myocardial ischemia, the method serves well under certain circumstances (20). Although traditionally used for operations on right heart, this technique is being increasingly used in adults for left heart operations like mitral valve replacement (21). The aorta is not cross clamped and the left side of heart is kept empty by continuous venting. Blood or air cannot pass the aortic valve as the pressure in the aortic root is higher. In patients with aortic insufficiency, the aorta is clamped and coronary sinus is perfused retrograde to keep the heart beating. This technique of beating left heart surgery has not yet been reported on a large scale in the pediatric population. 
Table 4 Comparison of different myocardial management techniques.

\begin{tabular}{|c|c|c|}
\hline Myocardial management & Advantages & Disadvantages \\
\hline \multirow{2}{*}{ Arrested heart } & - Decreased chances of air embolism & - Post clamp dysfunction \\
\hline & & $\begin{array}{l}\text { - Vent required (pulmonary artery vent may not suffice } \\
\text { if } \mathrm{Al} \text { is significant) }\end{array}$ \\
\hline \multirow{2}{*}{ Fibrillating heart } & - Technically easier & - Requires vent \\
\hline & - Quiet field & - Relative contraindication is $\mathrm{Al}$ \\
\hline Beating heart & - Avoids cross clamp & - Blood in field \\
\hline
\end{tabular}

Al, aortic insufficiency; TEE, transesophageal echocardiography.

Either of the above mentioned strategies can be used for certain operations like pulmonary valve replacement.

A comparison of the different myocardial management techniques is presented on Table 4.

\section{Profoundly bypothermic cardiac ischemia}

A number of studies have shown that deep hypothermia alone (15 degree $\mathrm{C}$ or less) provides better or equivalent myocardial protection in infants compared to the use of hypothermia with addition of cardioplegia $(22,23)$. The heart is profoundly cooled by systemic hypothermia and topical cooling and the aorta is cross clamped. This provides 45 to 60 minutes of safe cardiac arrest (24). This method may be useful in infants when there is a doubt about the cardioplegia delivery and the heart function is already poor as for example in case of anomalous left coronary artery from the pulmonary artery where the cardioplegia delivery has not been satisfactory for some reason. A single dose of cardioplegia is considered adequate for myocardial protection at deep hypothermia in neonatal age group by many surgeons (25).

\section{Manipulation of CPB flows}

Varying the arterial flow and venous return may be advantageous to the surgeon in certain situations. Knowledge of this may prove handy in difficult situations.
At full flow $\mathrm{CPB}$ the arterial flow into the patient is equal to the venous return into the reservoir. At normothermia a flow index of $2.4 \mathrm{~L} / \mathrm{min} / \mathrm{m}^{2}$ is considered full flow CPB although lower indices can be used at lower temperatures. In certain situations the CPB flow rate may have to be increased above what is considered an appropriate index for the temperature.

(I) Low venous saturations. This is usually correctable by raising the hematocrit on pump;

(II) coronary air embolism. This is done to achieve a higher pressure head to drive out the air from the coronaries;

(III) compensation for steal from systemic circulation e.g., tetralogy of Fallot with pulmonary atresia situation, where one is not able to control the flow from collaterals;

(IV) carotid or renal artery stenosis. This is again to achieve a higher pressure head and can be used in addition to vasopressors;

(V) persistently low perfusion pressure. This is in addition to vasopressors;

(VI) expedite rewarming or cooling.

Unequal flows are not sustainable as it would result in either emptying of the patient or the reservoir of the $\mathrm{CPB}$ machine. However, one can use transient unequal flows in certain situations to one's advantage (Figure 2). The blood volume of the patient can be shifted to either the reservoir of the CPB machine (e.g., in circulatory arrest) or vice versa 
MANIPULATION OF CPB FLOWS

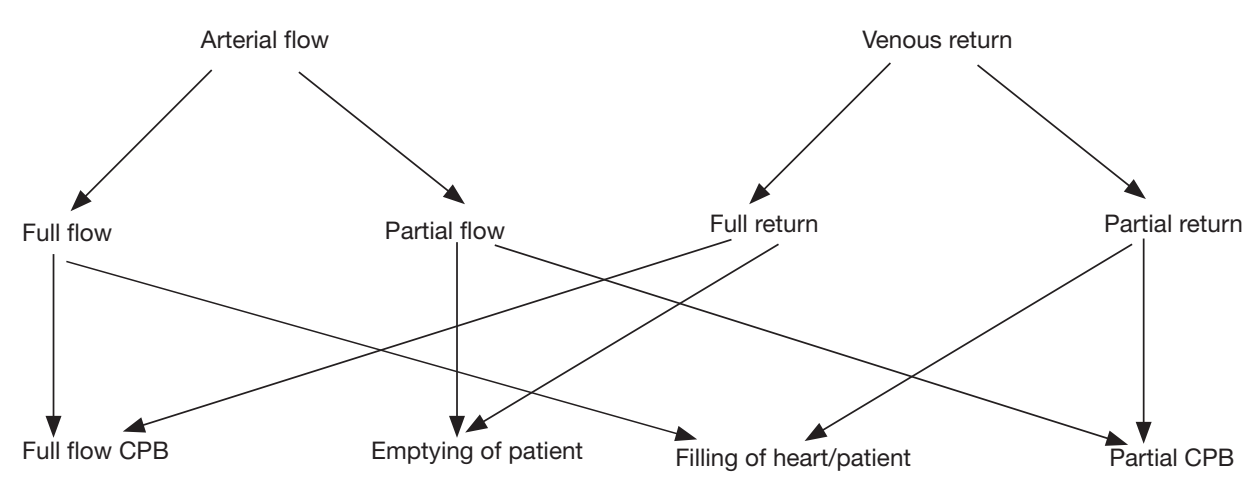

Figure 2 The possible manipulation of flows on CPB and its effects. CPB, cardiopulmonary bypass.

by altering the relative flows in the arterial and venous limbs of the cardiopulmonary machine.

Patient volume can be either wholly or partially shifted to the reservoir by decreasing arterial flow while keeping venous drainage the same. This ultimately results in exsanguination of the patient. Transient decrease in arterial flows is useful in the following situations.

(I) To decrease blood in the field. This is especially useful when collateral flow is overwhelming and visualization of the operative field becomes difficult. However continuous monitoring of venous saturations is necessary to avoid tissue ischemia. Systemic cooling is useful when such a situation is anticipated;

(II) unexpected ventricular distension e.g., undetected patent ductus arteriosus;

(III) aortic dissection or tear to avoid progression of tear;

(IV) ligation of a large patent ductus arteriosus to avoid rupture of ductus.

Unexpected or expected decrease in arterial flows should be matched by decreasing venous returns to prevent patient exsanguination e.g., arterial cannula obstruction or small arterial cannula. This is essentially a situation of partial $\mathrm{CPB}$ and may be experienced when peripheral cannulation permits less than ideal size arterial cannula in a redo situation. Similarly reservoir volume can be deliberately shifted to the patient by maintaining the arterial flow while decreasing the venous return. This ultimately results in emptying of the reservoir. Decreasing venous return is useful in the following situations:

(I) to fill up the heart just before placing the left atrial vent;
(II) to distend the SVC for cannulation;

(III) to deair the heart;

(IV) to impart ejection (when heart is beating).

Unexpected or expected decrease in venous return should be matched by decrease in arterial flow to prevent emptying of reservoir e.g.,

(I) sudden airlock;

(II) manipulation of venous cannula.

\section{Sternotomy and access to the arterial and venous systems}

Gaining access to the systemic arterial and venous systems is the first step in establishing CPB. The approach is usually straightforward in the first operation when aorta and both the cavae or the right atrium are easily accessed. This can however be a challenge in a redo situation when the heart, aorta or the pulmonary conduit are closely adherent to the sternum. In such cases, alternate sites of arterial and venous cannulation may have to be sought. The neck vessels (in patients weighing less than $15 \mathrm{kgs}$ ) or femoral vessels (in patients weighing more than 15 to $20 \mathrm{kgs}$ ) can be used for establishment of safe CPB. This also leads to decompression of the heart enabling safer dissection. Even partial CPB and the resulting decompression of the heart when the peripheral vessels are small can provide safe conditions for dissection. Once the heart is exposed, additional venous cannula can be placed for a bicaval cannulation as the need may be. Decision to use peripheral cannulation or expose the vessels in a redo case is based on degree of adhesion of the heart to the sternum as judged by imaging investigations and operator experience. Even when the 
Table 5 Before redo sternotomy

1. Make sure blood is available in the room

2. Defibrillator pads on patient

3. Rapid blood infuser

4. Alternate site of cannulation ready (good idea to mark the site of femoral pulsation on the groin)

5. Prepare lines and be ready for cannulation in difficult cases

Table 6 Checklist for deciding cannulation

1. Understand the anatomy; e.g., L posed aorta/interrupted IVC, left SVC

2. Review CXR/angiogram/CT and MRI to assess the position of the heart relative to the posterior table of the sternum and the vessels available (can often be occluded) for cannulation. Get an idea of the size of vessel

3. Palpate the peripheral vessels and mark the site

IVC, inferior vena cava; SVC, superior vena cava.

Table 7 Simple strategy in redo cases

Heart not adherent or low risk: proceed with redo sternotomy

Doubtful or medium risk: expose the neck or groin vessels before redo sternotomy

High risk: Peripheral cannulation (after heparinization), CPB and cooling before sternotomy*

*, avoid excessive cooling in aortic regurgitation to avoid ventricular fibrillation and myocardial distension. CPB, cardiopulmonary bypass.

peripheral vessels are small, one can use partial flows, cool the patient and decompress the heart. Some tips concerning redo sternotomy are presented on Tables 5-7.

\section{Preliminary dissection of the aorta and cavae- extracardiac dissection}

Preliminary dissection of the aorta and right atrium or both cavae is necessary to facilitate cannulation. Dissection should provide enough room for purse string and cannulation at a minimum and application of aortic cross clamp or caval snares when necessary. In difficult situations, the vessels can be dissected safely once they are cannulated and CPB is established or alternative strategies can be employed (ventricular fibrillation for difficult aorta and advancement of right atrial cannula into vena cava). In some situations, the great vessels may be scarred so badly that it may become difficult to differentiate the aorta from the pulmonary artery or RV to PA conduit. In such cases one can use a needle to record the pressure tracing to differentiate between them.

The extracardiac dissection at this stage (preCPB) is limited by hemodynamic instability and bleeding in high risk cases (e.g., scarred conduit). Blood is lost to external suction if patient is not heparinized or a cell-saver is not in use. If patient is heparinized, it can be suctioned into the reservoir. If the arterial cannula is already in place and the patient is hemodynamically unstable, one can go on suction $\mathrm{CPB}$ and gain venous access to commence $\mathrm{CPB}$.

\section{Heparinization}

Heparin is most often administered by the anesthesiologist into a central line. If there is a doubt of the venous access, it is a good idea for the surgeon to administer the heparin directly into the RA. A high ACT is a must to prevent clot formation in the circuit. It is a good idea to request for heparin administration early in the course of an easy dissection to give 4 to 5 minutes for the heparin to distribute and act. Aortic and bicaval or RA purse strings should be placed now for cannulation.

An accepted protocol of action based on ACT level (institutional practices vary) is presented in Table 8 .

\section{Preparation of CPB circuit lines}

Once the purse strings are in place, the surgeon should get the CPB lines ready ahead of cannulation. Institutional practices vary with regards to the position of the $\mathrm{CPB}$ machine with respect to the surgeon (front or behind). Sufficient length and occlusion should be checked on both arterial and venous sides. The venous side should be tailored for single RA venous cannulation, double venous cannulation (by adding a Y connector to the venous limb) or additional left SVC cannulation (double Y connectors on the venous limb). The lines should lie in a comfortable loop without kinks or redundancy and the lines should be firmly secured to the operative field.

\section{Cannulation of arterial and venous systems}

Perhaps the single most important step in establishing CPB is a safe arterial cannulation. Following this the right atrium 
Table 8 ACT based protocol for cardiopulmonary bypass

\begin{tabular}{lll}
\hline ACT & Action & Rationale \\
\hline$<100$ & Arterial cannulation & $\begin{array}{l}\text { Pump suckers not efficient as wall suckers to mop up brisk bleeding } \\
\text { from aorta. Blood is lost to external suction }\end{array}$ \\
$>300$ & $\begin{array}{l}\text { Pump suckers on and venous } \\
\text { cannulation }\end{array}$ & Pump suckers can keep up with venous bleeding (suction bypass) \\
$>400$ & Commence CPB & At such high ACT any chances of clotting in circuit are minimal \\
\hline
\end{tabular}

$\mathrm{CPB}$, cardiopulmonary bypass; ACT, activated clotting time.

Table 9 Tips for safe cannulation for cardiopulmonary bypass

Before cannulation

Plan site of purse string

Confirm size of cannulae

Essential steps of arterial/ venous cannulation

Cannulation-Incision on vessel wall followed by introduction of blunt instrument into the lumen should precede actual cannulation (to avoid dissection)*

Securing - the cannula should be tied firmly to the snare to prevent accidental slip of the cannula

Division of cannula when necessary to enable connection to the arterial line.

Deairing - thorough deairing of cannula especially when it is arterial. Some amount of air is permissible on the venous side.

Connection-establish a tight connection between the cannula and the line

Fixing - the cannulae should be laid down without any kinks and fixed in place

*, a greater depth of cannulation may be required for aorta in redo situation.

Table 10 Strategies for venous cannulation

\begin{tabular}{ll}
\hline Staged bicaval cannulation & Direct bicaval cannulation \\
\hline $\begin{array}{l}\text { Method of cannulation for sick hearts or difficult anatomy (when } \\
\text { exposure of IVC can lead to severe hypotension) }\end{array}$ & Method of cannulation for most patients \\
RA and SVC are cannulated first followed by shift of RA cannula to IVC & SVC cannulation is followed by cannulation of IVC or vice versa* \\
\hline *, some surgeons institute CPB with just IVC cannula before establishing flow through SVC cannula. Achievement of at least half flows \\
through the IVC cannula alone rules out selective cannulation of a hepatic vein. CPB, cardiopulmonary bypass; IVC, inferior vena cava; \\
SVC, superior vena cava.
\end{tabular}

or cavae are cannulated. Suction bypass can be instituted if venous cannulation becomes difficult. The arterial and venous cannula are the lifelines and perhaps the weakest links in the connection between the external pump and the patient. Extra precaution should be exercised to secure these cannula. Some useful tips for cannulation are presented in Table 9.

The perfusionist must be able to record a good pulsation from the arterial line at the end of aortic cannulation. Alternate sites of cannulation are the base of the innominate artery, carotid and femoral arteries.
Venous cannulation can be achieved in different ways as shown in Table 10.

The indications for RA and bicaval cannulation are shown in Table 11.

Innominate vein cannulation may be used where the SVC needs to be worked upon .e.g. in Warden operation. Alternate site is the internal jugular vein. Similarly femoral venous cannulation may be used when one needs to work low on the IVC e.g. in extracardiac Fontan operation or inferior type of sinus venosus ASD. 
Table 11 Indications for venous cannulation

\begin{tabular}{|c|c|}
\hline RA cannulation & Bicaval cannulation \\
\hline 2. Difficult SVC/IVC cannulation. Advance RA cannula into SVC/IVC & $\begin{array}{l}\text { 2. For left heart surgery when retrograde cardioplegia is planned } \\
\text { via open method. }\end{array}$ \\
\hline 3. Smallish SVC (to prevent SVC stenosis) & $\begin{array}{l}3 \text { To achieve total CPB when myocardial protection is critical e.g., } \\
\text { In as case of ALCAPA with severely depressed LV function }(26,27)\end{array}$ \\
\hline
\end{tabular}

SVC, superior vena cava; IVC, inferior vena cava; CPB, cardiopulmonary bypass.

\section{Management of left SVC}

Persistent left SVC is present in $2 \%$ to $10 \%$ of population with congenital heart disease. This incidence increases to $40 \%$ in patients with abnormal situs (9). In most cases it drains into RA. In $10 \%$ it drains into LA. Occasionally there are defects in the wall of the coronary sinus leading to a type of atrial septal defect.

The following issues may arise in presence of a left SVC during open heart operation.

(I) Retrograde cardioplegia. There could be a problem with balloon occlusion and dilution of cardioplegia by blood (28);

(II) Right heart entry/decompression. The operative field may be flooded with blood making any procedure on the right side of the heart difficult. The management options are:

(i) Occlusion of left SVC. When innominate vein is present, one can safely occlude left SVC except in the following situations:

(a) Rare possibility of atresia of coronary sinus. Occlusion of left SVC can cause myocardial injury (29);

(b) Absence of right SVC. When innominate vein is absent, occlusion may cause cerebral injury. This should only be done for a short duration while documenting venous pressure cephalad to site of occlusion;

(ii) Selective cannulation of left SVC;

(iii) Cardiotomy suction in the LSVC with caval occlusion.

\section{Suction $C P B$}

In some cases, it may be advantageous to use suction CPB for a brief duration to avoid dissection and snaring of badly adherent cavae. Suction CPB causes increased hemolysis and is not as efficient as closed venous bypass $(30,31)$. The advantages and disadvantages of this technique are presented on Table 12.

\section{Performance of IVC cannula}

It is critical to note the performance of the IVC cannula on $\mathrm{CPB}$. The IVC cannula being the larger cannula not only drains the IVC but also the coronary sinus return. This can be noted as good collapse of the RA on CPB. Occasionally the cannula may not be very effective and blood can flow around the cannula into the RA. The knowledge of this is important towards end of operation when the IVC is desnared. If the cannula was effective in draining the coronary sinus return earlier, then de-snaring the IVC may be helpful in decompressing the right heart. If, however the cannula had not draining well, then de-snaring may result in more distension of the right side. In such cases, it is worthwhile to delay de-snaring until the contractility has improved (see Figures 3,4).

If RA is not opened for the majority of operation, then it is a good idea to leave the larger venous cannula in RA and shift to IVC only when RA needs to be opened. The cannula drains better in RA position than when positioned in IVC. An alternate strategy is to turn the cannula upwards until RA needs to be opened. The cannula can be turned down into the IVC and snared just before RA incision.

\section{Institution of CPB}

When transitioning the work of the heart to an external machine, precaution must be exercised. It is a good practice to keep looking at the heart as $\mathrm{CPB}$ commences. One must look at the ascending aorta for any signs of dissection and the RA for decompression indicating good venous return. 
Table 12 Comparison of suction and conventional closed cardiopulmonary bypass

\begin{tabular}{lll}
\hline & Suction CPB & Conventional closed CPB \\
\hline Advantages & Can be employed on emergent basis & More efficient \\
& Avoids dissection around cavae & Lesser hemolysis \\
Disadvantages & Less efficient circulation. Need to cool to accept lower flows; & More dissection involved especially if cavae \\
& more hemolysis; major source of lipid micro emboli (32) & are cannulated and snaring is necessary \\
\hline
\end{tabular}

CPB, cardiopulmonary bypass.

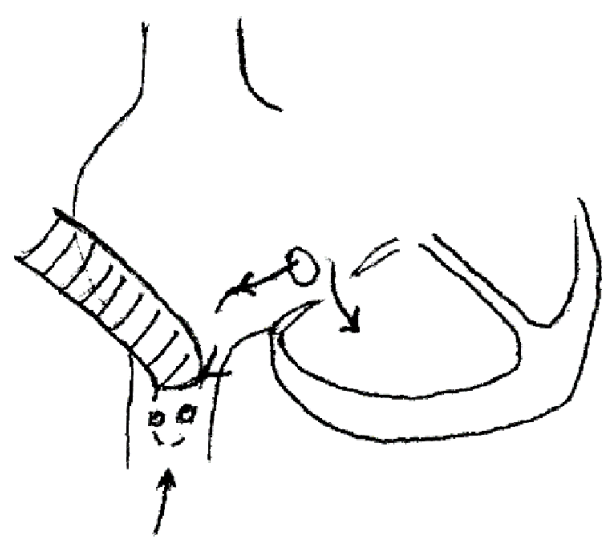

Figure 3 Optimal drainage of IVC cannula. IVC cannula drains entire IVC return and some of the CS return. A beating RV handles the rest of the CS return but distends during cardiac arrest. IVC, inferior vena cava; RV, right ventricle.

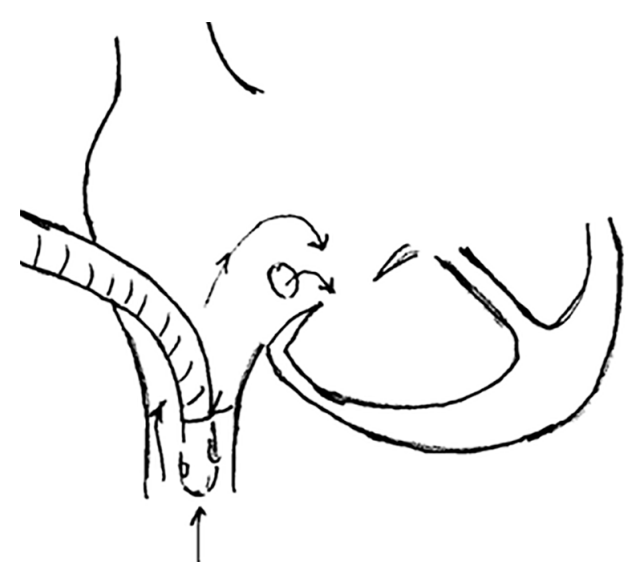

Figure 4 Poor drainage of IVC cannula. IVC cannula barely drains entire venous return. Snugging of IVC often improves return. IVC, inferior vena cava.

Some useful tips while instituting CPB are listed in Table 13.

Ideally there should be minimal or no ejection with a well collapsed RA. When ejection is significant one should
Table 13 Tips during institution of cardiopulmonary bypass

\begin{tabular}{l} 
Before institution of CPB \\
Confirm ACT $>400 \mathrm{sec}$ \\
After institution CPB \\
Full flows with no arterial pressure alarm and good collapse of \\
RA (keep eyes on the heart while going on CPB) \\
Initiate cooling to target temperature \\
Stop ventilation \\
Ligate/control systemic pulmonary connections \\
\hline CPB, cardiopulmonary bypass; ACT, activated clotting time.
\end{tabular}

think of:

* aortopulmonary shunt. e.g., TOF.PA with aortopulmonary collaterals;

* aortic insufficiency.

Improper venous drainage can result in ejection. However, this can be detected by a poorly collapsed RA or a CVP greater than zero. Causes of decreased venous return and arterial flow are listed in Table 14.

It is important to understand that anything that causes significant ejection while the heart is beating on CPB can result in distension if the heart loses contractility or is arrested.

\section{Concept of left beart bypass}

In an emergency or abnormal situs, one can cannulate the left atrium if that is more readily accessible (33). The lungs can be kept ventilated or deflated. The perfusionist should be warned of red color of the venous return when lungs are kept ventilated. The cannula can be shifted once access is gained to the RA.

\section{Ligation or control of systemic pulmonary shunts}

The presence of systemic pulmonary shunts can lead to 
Table 14 Causes of decreased venous and arterial flows

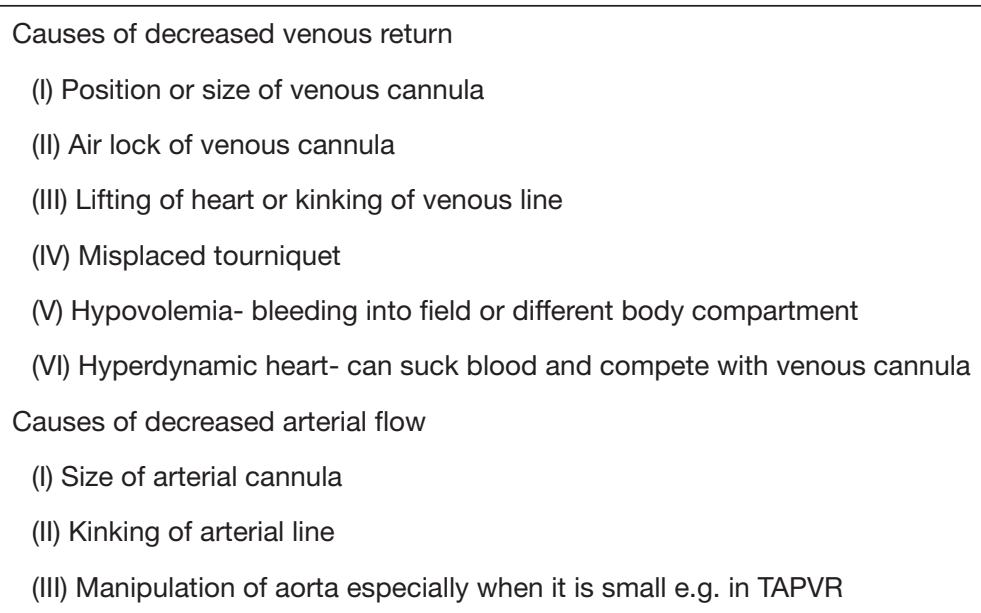

TAPVR, total anomalous pulmonary venous connection.

Table 15 Comparison of normothermia and hypothermia during cardiopulmonary bypass

\begin{tabular}{lll}
\hline & Normothermia & Hypothermia \\
\hline Advantages & Lesser inflammation; Lesser coagulopathy & $\begin{array}{l}\text { Ability to reduce flows and decrease blood in field; greater } \\
\text { degree of safety to the brain (35) }\end{array}$ \\
Disadvantages & $\begin{array}{l}\text { Little room for decreasing flows in case of accidents } \\
\text { or to reduce blood in operative field; } \text { neuroprotection } \\
\text { is theoretically lesser }\end{array}$ & $\begin{array}{l}\text { Coagulopathy (36); impaired drug metabolism; prolonged } \\
\text { recovery from anesthesia (37); diaphragmatic dysfunction (37); } \\
\text { wound infections; myocardial dysfunction (38) }\end{array}$ \\
\hline
\end{tabular}

*, this often entails more dissection for example of the pulmonary artery branches to decrease blood in field by snaring them. Moreover, the dissection itself can cause more bleeding.

hypotension due to runoff into the pulmonary vascular bed. Hence it is important to control these as soon as bypass is initiated. When these cannot be controlled as for example MAPCAs in TOF.PA, one should either keep the heart beating (using normothermic normocalcemic CPB strategy) or use higher flows (to compensate for the steal of blood from the systemic circulation) and adequate venting for the increased left heart return. Examples of systemic pulmonary shunts include:

$$
\begin{aligned}
& \text { * PDA; } \\
& \text { * BT shunt; } \\
& \text { * MAPCAs. }
\end{aligned}
$$

An undiagnosed PDA or shunt manifests as persistent poor systemic pressure and can sometimes lead to sudden LV distension. Diagnostic pointers are decreased perfusion pressure, dilated main pulmonary artery, distended $L V$ and right heart distension in presence of a VSD or pulmonary insufficiency. Emergent interventions in such cases include:

(I) decrease CPB flows immediately;

(II) vent the heart;
(III) dissect and ligate PDA;

(IV) restore normal flows.

\section{Initiation of systemic cooling to target temperature}

The plan to use a certain degree of hypothermia should be made in advance. Practices vary widely and the operator has to choose the strategy he or she is most comfortable with. At the moment there is no good evidence supporting one strategy over the other in the pediatric population although there is some data emerging in the adult population (34). Table 15 shows the potential advantages and disadvantages of the two strategies. Some useful tips during cooling are listed in Table 16.

\section{Placement of LA vent}

The left side can be vented via different routes such as right superior pulmonary vein, left ventricular apex, left 
Table 16 Tips for cooling on cardiopulmonary bypass

While initiating cooling

- Rule out AR. Be prepared to clamp aorta when starting to cool

- If MAPCAs cannot be controlled or ligated use normothermic normocalcemic CPB. If heart has to be arrested, cool the patient to deep hypothermia or used increased flows and large vent

AR, aortic regurgitation; MAPCA, Major aortopulmonary collateral arteries.

Table 17 Comparison of timing of LA vent placement

\begin{tabular}{lll}
\hline LA vent placement & Advantages & Disadvantages \\
\hline Before cross clamp & $\begin{array}{l}\text { One less thing to do following application of } \\
\text { cross clamp and eliminates any chances of } \\
\text { heart distension. }\end{array}$ & $\begin{array}{l}\text { Air embolism (keep the heart full by decreasing venous } \\
\text { drainage while placing LA vent) }\end{array}$ \\
After cross clamp & No chance of air embolism & $\begin{array}{l}\text { Potential for heart distension especially when there is } \\
\text { increased left heart return }\end{array}$ \\
\hline
\end{tabular}

LA, left atrium.

atrial appendage or pulmonary artery. In difficult redo situations the left side can be vented by opening the right atrium and creation of a defect in the atrial septum. When there is significant collateral return, the vent in the right superior pulmonary vein is more advantageous compared to a vent across the atrial septum as it provides continuous decompression of the LV immediately after application and removal of the aortic cross clamp when the $\mathrm{LV}$ contractility is poor. The LA vent can be placed before or after application of cross clamp. The advantages and disadvantages of either approach are listed in Table 17.

Special situations of left side venting:

(I) Single ventricle situation. Left side is vented across the atrial septal defect (ASD) through the venous cannula. When the heart is arrested and cannula are snared, it is important to either place an additional vent or open one of the atrial chambers.

(II) Repair of ostium secundum ASD. Usually no vent is placed. The right atrium is opened as soon as the heart arrests and the left side vents across the ASD. Earlier rewarming restores cardiac activity as soon as clamp is released. Cardiac massage may be rarely needed to prevent distension.

(III) Supracardiac TAPVR. Vertical vein acts as vent both during cooling and rewarming and should not be ligated till LV has regained contractility.

(IV) Infracardiac TAPVR. Vertical vein is incised open (open vent) during cooling and should not be ligated earlier to opening. Earlier rewarming or massage may be necessary to prevent distension during rewarming.

Following placement of the LA vent, one can snare the IVC and SVC if there is an atrial communication. If there is no atrial communication and the right side has lost contractility, the IVC cannula should be allowed to drain the coronary sinus return. It is extremely important to be cognizant of the coronary sinus return (blood before aortic cross clamp and cardioplegia after aortic cross clamp application) to avoid right heart distension.

\section{Extracardiac dissection}

\section{This has three components}

(I) Dissection around ascending aorta for application of cross clamp and around vena cavae for snares;

(II) essential extracardiac dissection for the particular operation.

The branch PAs need to be mobilized well for an arterial switch operation while the azygous vein needs to be ligated for a bidirectional Glenn. Such extracardiac dissection or mobilization is different for every operation. Much of the extracardiac dissection should be done on CPB to decrease cross clamp time just as dissection done prior to going on $\mathrm{CPB}$ decreases CPB time. Simple parts of repair can also be completed e.g., marking sutures should be placed on RVOT or ascending aorta. Although hemodynamic 
Table 18 Checklist during application of aortic cross clamp

\author{
Before applying cross clamp \\ Completion of all necessary dissection \\ Set up cardioplegia delivery system set up \\ Plan for adequate venting of cardioplegia \\ After applying cross clamp \\ Adequate root pressure (by palpation) when antegrade CPG is used and adequate pressures (by monitor) when retrograde CPG is used \\ Confirm cardioplegia return through coronary sinus with antegrade cardioplegia and coronary ostia with retrograde cardioplegia \\ Heart should be flaccid \\ Rapid disappearance of electric activity \\ Avoid kinking of coronaries that will prevent perfusion of cardioplegia \\ Whenever possible deair aortic root by making the aortic valve incompetent before delivery of repeat dose of antegrade cardioplegia
}

instability is no longer an issue, factors limiting the extent of this dissection on $\mathrm{CPB}$ are:

(i) coronary ischemia: it is important to realize that significant potential for myocardial ischemia exists when the aorta is pushed or pulled around while on $\mathrm{CPB}$ as these maneuvers result in kinking of coronary arteries (dramatically seen when the diminutive aorta in HLHS is pulled or pushed around);

(ii) aortic regurgitation: the same maneuvers can result in aortic insufficiency and distension (especially when heart has lost contractility).

(III) Tailoring of the homograft. Myocardial arrest time can be reduced by proper sizing and tailoring of the homograft before application of cross clamp e.g., aortic cross clamp time can be significantly reduced if bicuspidization of pulmonary homograft is performed before the heart is arrested.

\section{Setting up cardioplegia delivery system}

The cardioplegia system should be planned for each patient. It is a good idea to have both a retrograde and direct ostial cannula on the table when an aortotomy is performed. A pressure monitoring system and small syringe are necessary for retrograde cardioplegia delivery. It is good to zero the pressure line for retrograde cardioplegia delivery prior to aortic cross clamp.

\section{Cardiac arrest}

In cases where myocardial protection is in doubt, it is a useful strategy to employ systemic cooling to provide additional protection to the heart. Cooling not only decreases the temperature of the myocardium and hence the oxygen requirements but also allows decrease in $\mathrm{CPB}$ flows and hence the left heart return that tends to wash out the cardioplegia.

\section{Venting of cardioplegia return}

It is essential to formulate a plan for venting the cardioplegia. When the IVC cannula has been draining the coronary sinus return well, one can use it to vent the cardioplegia return before snaring it. If, however the cannula has not been draining well, then the right heart could distend with the coronary return unless the RA is opened or it is drained across an atrial septal defect by a cannula in left atrium. Table 18 presents a check list before and after application of aortic cross clamp.

\section{Circulatory arrest}

When one needs to work on the aorta (beyond site of arterial cannulation) or IVC (below site of venous cannulation), blood flow will have to be essentially stopped to enable surgical work. Hypothermia provides protection during these stages of reduced flow.

(I) It is important to realize that circulatory arrest also shuts off coronary blood flow and is physiologically equivalent to a cross clamp. Therefore, one must always use cardioplegia to protect the heart during this period. In other words, cross clamping and 
Table 19 Comparison of strategies for aortic cross clamp following initiation of circulatory arrest

\begin{tabular}{lll}
\hline Strategy & Indication & Required actions \\
\hline $\begin{array}{l}\text { Circulatory arrest and removal of } \\
\text { cross clamp }\end{array}$ & $\begin{array}{l}\text { When clamp obstructs field and needs to } \\
\text { be removed }\end{array}$ & $\begin{array}{l}\text { Reapply cross clamp when flows reinitiated; deair } \\
\text { ascending aorta before removal of clamp }\end{array}$ \\
Circulatory arrest and clamp kept on & When clamp does not interfere with work & $\begin{array}{l}\text { Keep clamp on when flows are reinitiated (if } \\
\text { intracardiac operation remains). e.g., VSD repair } \\
\text { following arch augmentation }\end{array}$ \\
& & $\begin{array}{l}\text { Remove clamp at time of restart of flows if no } \\
\text { intracardiac operation remain. E.g., Isolated arch } \\
\text { augmentation }\end{array}$ \\
\hline
\end{tabular}

VSD, ventricular septal defect.

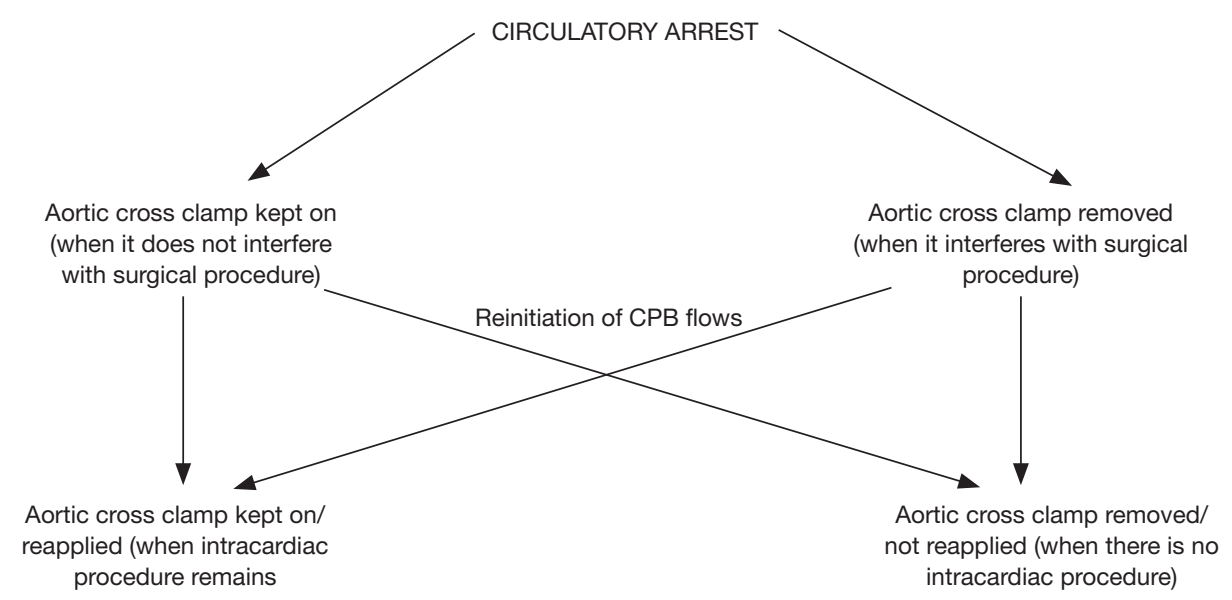

Figure 5 Comparison of strategies for aortic cross clamp following circulatory arrest. CPB, cardiopulmonary bypass.

cardioplegic arrest must always precede circulatory arrest. The cross clamp can be either be kept on during the arrest or removed to facilitate operation. If the cross clamp is removed, one must remember to reapply it when flows are reinitiated for continued arrest of the heart (if intracardiac operation still remains). It is also important to deair the ascending aorta to prevent coronary and cerebral air embolism when the cross clamp is taken off. The two approaches are summarized in Table 19 (also see Figure 5).

(II) During cooling to deep hypothermia, cardioplegic arrest of the heart can be done at any point. Intracardiac procedure can be done during the mandatory cooling period (often 20 minutes). If the heart fibrillates earlier to clamping, it is important to keep it vented to prevent distension.

(III) Similarly, the aortic cross clamp can be removed at any time point during rewarming so far as the heart is vented well enough until it regains its contractility.

(IV) Single dose of cardioplegia is sufficient during myocardial arrest at deep hypothermia in up to 2 to 3 months of age (25). Multiple doses are required in older age group.

(V) Intermittent perfusion to interrupt circulatory arrest when time constraints are anticipated is useful (11). Some authors believe that if the brain is perfused between periods of circulatory arrest, the durations of circulatory arrest are not additive $(39,40)$.

(VI) An inaccurate repair of the heart (especially possible when there is increased collateral flow and blood in the field) can produce significant damage in the long term. This risk should always be weighed in when deciding the necessity of circulatory arrest and its duration. Circulatory arrest can also be used in neonates or small single ventricle infants where 
Table 20 Checklist for circulatory arrest

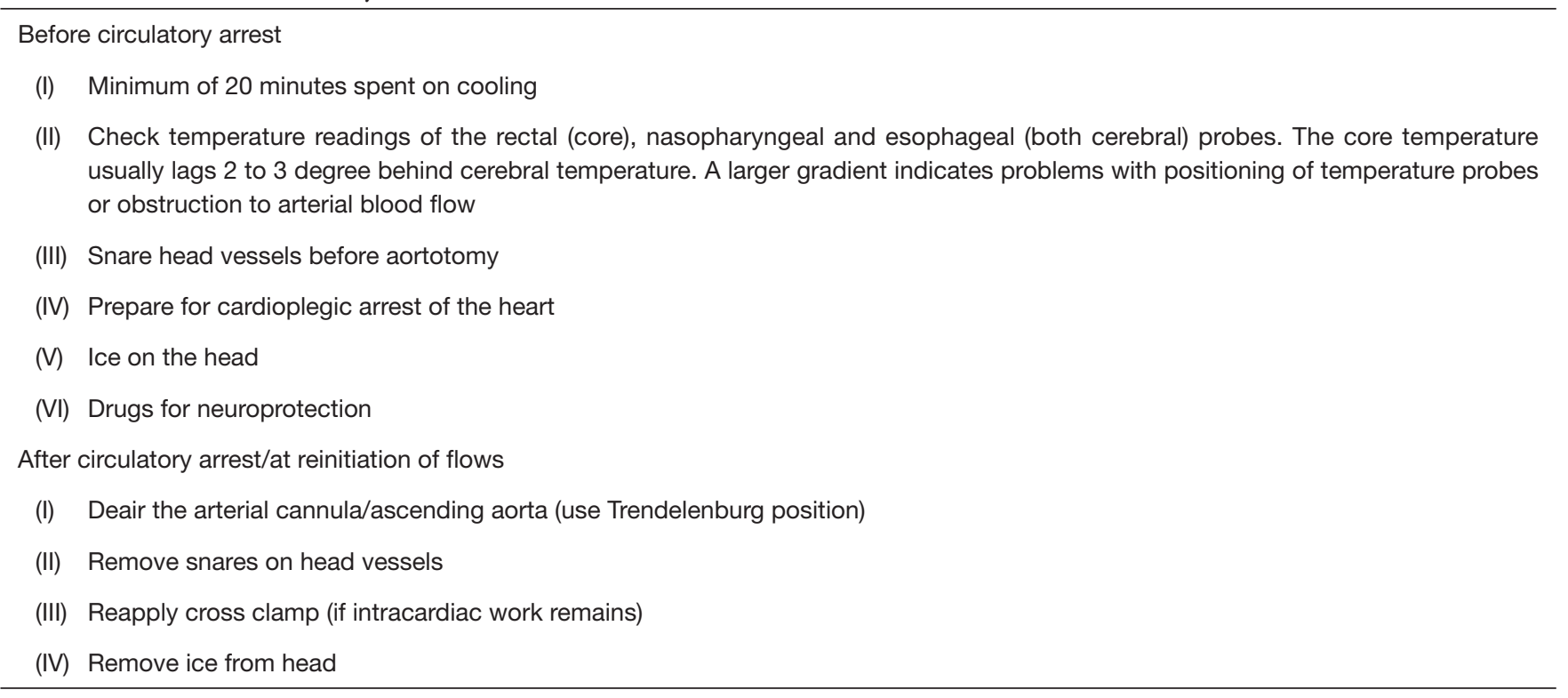

one wishes to avoid cannulation of the SVC and potential narrowing of it.

A check list before and after circulatory arrest is presented in Table 20.

It is important to deair the arterial cannula and ascending aorta by using trickle flows before establishing full flows. The surgeon or the perfusionist should clamp the venous cannula before removing it from the atrium.

\section{Intracardiac procedure}

Whenever the right atrium needs to be opened, it is important to snare the cavae to prevent air entrainment. Therefore in a case with no atrial communication following aortic cross clamping one can either wait for the IVC cannula to drain the cardioplegia or snare the IVC and quickly open the RA.

Snaring cavae is necessary whenever the right side has to be opened. Exceptions are:

(I) opening RA during circulatory arrest;

(II) opening RV when TV is competent and tricuspid chordae are not in area of work.

Snaring cavae is also essential when LA is opened in presence of an ASD.

Myocardial protection is maintained by intermittent administration of cardioplegia with a continuous watch on electrical activity. Intermittent cardioplegia is often used at intervals of 20 to 30 minutes either as full or half doses for St. Thomas cardioplegia. This 20 -minute rule can be violated in some circumstances. Del Nido cardioplegia is often repeated every 45 to 60 minutes.

(I) When only a little more time is needed to complete the repair;

(II) questionable activity of the heart. When in doubt, run additional doses of cardioplegia;

(III) bursts of cardioplegia can be used to distend the aortic root and observe leaflets either to define the annulus or rule out injury to the aortic valve;

(IV) when an alternate/easier route of cardioplegia delivery may not be available for a while, e.g., during arterial switch operation, one may use cardioplegia ahead of the due time to buy full 20 minutes to reimplant the coronaries.

(V) a single dose of cardioplegia is generally sufficient for neonates at deep hypothermia.

Whenever possible, it is important to deair the aortic root and cardioplegia line ahead of cardioplegia delivery e.g., one can deair the aortic root by making the aortic valve incompetent during closure of a VSD.

\section{Initiation of rewarming}

The initiation of rewarming (if hypothermia has been used) usually marks the first step towards weaning the patient from the CPB machine. Usually rewarming precedes removal of the cross clamp to allow the warm blood to restore heart 
Table 21 Strategies for rewarming on cardiopulmonary bypass

\begin{tabular}{|c|c|c|}
\hline Strategy & Mechanism & Example \\
\hline $\begin{array}{l}\text { Earlier rewarming before removal of } \\
\text { aortic cross clamp }\end{array}$ & & $\begin{array}{l}\text { Expected residual AR following valve repair or } \\
\text { unrepaired mild to moderate AR }\end{array}$ \\
\hline \multirow[t]{2}{*}{$\begin{array}{l}\text { Delayed rewarming after removal of } \\
\text { cross clamp }\end{array}$} & Hypothermia reduces heart rate & $\begin{array}{l}\text { - In TOF repair, the cross clamp can be removed } \\
\text { following infundibular resection and closure of VSD. } \\
\text { However, hypothermia may be continued during } \\
\text { patch augmentation of right ventricle outflow tract }\end{array}$ \\
\hline & & $\begin{array}{l}\text { Following construction of neo aorta in stage } 1 \\
\text { Norwood operation, hypothermia may be continued } \\
\text { during construction of proximal Sano shunt }\end{array}$ \\
\hline
\end{tabular}

ASD, atrial septal defect; AR, aortic regurgitation.

Table 22 Checklist for rewarming on cardiopulmonary bypass

Before initiating rewarming

(I) Think whether all the planned steps have been completed

(II) Whether to rewarm all the way or up to a certain level only

(III) Avoid complete rewarming especially if patient has undergone circulatory arrest or has propensity for junctional ectopic tachycardia

activity and contractility faster. However, if the intention is to keep the heart quiet, hypothermia can be continued while the cross clamp is removed to decrease the myocardial ischemia time. In such cases venting of the left heart is usually required. Examples of both approaches are listed in Table 21. Rewarming can either be done all the way up to normothermia or in stages as the operation progresses. Table 22 presents a check list for initiating rewarming.

\section{Deairing of heart}

This is a key step of open heart surgery. The price for inadequate deairing can be high in the form of cerebral or coronary air embolism. Sites for deairing the heart are gaps in suture line of septal patches or LA incision and cardioplegia needle site.

Deairing is often easier in cyanotic patients when there is increased left heart collateral return than in left to right shunts. To initiate the process of deairing, the LA vent has to be shut off and the heart allowed to fill (with blood or normal saline) before closing to minimize air entrapment. This is based on the amount of left heart return observed during operation. The lesser the return, the earlier the process of filling the left heart should be initiated. In addition saline can be used to deair the heart in such cases. It is important to deair the right side as much as possible before closure of the chambers. In the presence of $\mathrm{AV}$ fistulae, air from the right side can enter the systemic circulation. Intermittent or continuous carbon dioxide insufflation into the operative field is an effective method to decrease air trapping within the chambers of the heart and the great vessels.

Deairing continues after removal of cross clamp. Either the aortic vent site is allowed to bleed or an active root vent is used. It has become a standard practice now to use TEE to rule out air in the heart following removal of the root vent (41). The steps of deairing are listed in Table 23.

\section{Removal of cross clamp}

In general the aortic cross clamp is removed as soon as the left heart is completely closed (purpose of the clamp here is to prevent air embolism). Exceptions are made when delicate suturing has to be done e.g. outflow tract patch close to LAD (purpose of clamp here is to keep the field still). In a single ventricle situation, the clamp is removed 
Table 23 Steps of deairing heart

Allow the heart to fill (with blood or normal saline)

Massage heart gently to express air out. This is continued until no more air is seen coming out through the aortic root vent

The lungs may be gently ventilated to express air from pulmonary veins (vigorous over inflation should be avoided)

Place patient in Trendelenburg position

Remove the aortic cross clamp with ostium of RCA occluded (to prevent coronary air embolism)

Continuous suction is applied over the aortic root vent

TEE should be used to confirm complete removal of air from left side

A large bore needle may be used to aspirate air from difficult pockets like LA or LV apex

$\mathrm{RCA}$, right coronary artery; LA, left atrium; LV, left ventricle.

Table 24 Checklist for removal of aortic cross clamp

Before removal of cross clamp
Stop LA vent
Deair adequately
Reduce flows
Trendelenburg position (to prevent cerebral air embolism)
After removal of cross clamp
Restart LA vent and aortic root vent
Go up on flows again

LA, left atrium.

Table 25 Checklist for removal of LA vent

Before removal of LA vent

TEE confirmation of absence of air in left heart

Make sure heart is filled. Look both at the heart and monitor for ejection. (There could be ejection with an empty LA in aortic insufficiency)

Remove vent during inspiration (when lungs are inflated)

LA, left atrium.

following deairing of the single ventricle. Table 24 presents a checklist for removal of aortic cross clamp. Sometimes profound hypotension can be experienced on release of aortic cross clamp especially when the clamp times have been long. This is related to release of cytokines from reperfusion of the myocardium.

When heart activity takes longer than usual to return following removal of cross clamp, think of:

(I) recent cardioplegia administration;

(II) high potassium level in blood;
Table 26 Hemodynamic monitoring during weaning of cardiopulmonary bypass

Temperature

ECG-rate, rhythm, conduction and any ischemia

Blood pressure: invasive and non-invasive

CVP: number and waveform

RA/LA pressure: number and waveform

PA pressure

Saturation

CVP, central venous pressure; RA, right atrium; LA, left atrium; PA, pulmonary artery.

(III)coronary air embolism.

\section{Separation from CPB}

Following removal of cross clamp, any incision on the right heart is closed. The snares over the cavae are removed. Preparations should be now made to come off CPB. Pacing wires should be placed over both the atrial and ventricular chambers. Intracardiac lines should be placed for access or monitoring of pressures if necessary. Ventilation is resumed and airway secretions are cleared. The LA vent is removed when contractility of heart has recovered (i.e., the heart is capable of handling the pulmonary venous return). It's always important to remove the vent under a fluid level of blood/ saline to prevent air embolism. Ejection is imparted to the heart to encourage deairing. The aortic root vent is removed when transesophageal echocardiogram (TEE) has confirmed absence of air and no more air is seen coming out of the cannula. Table 25 presents a checklist for removal of LA vent. 
Table 27 Checklist for removal of venous cannulae

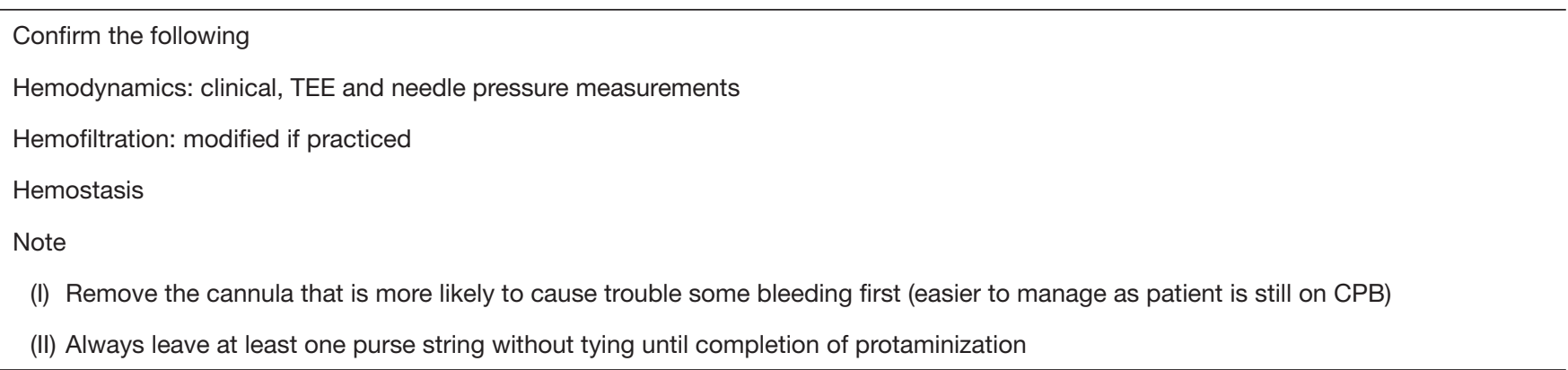

TEE, transesophageal echocardiogram; CPB, cardiopulmonary bypass.

Table 28 Checklist before sternal closure

Hemostasis should always be confirmed

Hemodynamics should be permissible for chest closure

Confirm placement of lines, tubes and pacing wires

Separation from CPB is a challenging part of open heart surgery requiring careful monitoring of multiple parameters and is well described in detail in other texts (42). Epicardial echocardiography and TEE have proved to be immensely useful in evaluating the adequacy of repair of complex congenital heart defects and guiding the surgeon $(43,44)$. Modified ultrafiltration appears to be beneficial in neonates and infants and results in elevation of hematocrit and generalized improvement in pulmonary and cardiac function $(45,46)$. Most pediatric centers today practice conventional or modified ultrafiltration. Table 26 presents a list of key hemodynamic parameters monitored during termination of $\mathrm{CPB}$.

\section{Venous decannulation}

The venous cannula can be removed from the right atrium or cavae following confirmation of satisfactory hemodynamics after separation from $\mathrm{CPB}$ and in the absence of major bleeding. When there is a single venous cannula in the RA, the patient has to be weaned completely off $\mathrm{CPB}$ before venous decannulation. When there are two cannula in both the vena cavae, one of the venous cannula can be removed as a part of weaning. A check list for venous decannulation is presented in Table 27.

\section{Arterial decannulation}

Following venous decannulation, protamine should be administered. Following administration of $1 / 3$ to $1 / 2$ dose of protamine and in the absence of a reaction to protamine, the arterial cannula can be removed. In cases of brisk bleeding, the arterial cannula can continue to be kept in place and used to resuscitate. The cannula can also be shifted to the right atrium and used for resuscitation in case there is bleeding at the cannulation site. In some situations, the aortic cannula can be relatively large compared to the size of the ascending aorta e.g., following TAPVR repair. In such a situation, the cannula can cause significant obstruction of the aorta and cause systemic hypotension. This should be taken into account before comparing the right and left sided pressures.

Following arterial decannulation the aortic purse string and the remaining venous purse string are tied (except when one expects to go back on $\mathrm{CPB}$ or $\mathrm{ECMO}$ ). Hemostasis is once again confirmed. The chest tubes are placed. The sternum is closed while continuously monitoring the hemodynamics. A brief check list for sternal closure is shown in Table 28.

\section{CPB emergencies and management}

In spite of the tremendous advances in techniques and perfusion education, there continue to be accidents on CPB $(5,47,48)$. Human error can never be completely eliminated and when such errors happen the surgeon more than anyone else should not panic. Calm and deliberate movement is more effective than frenetic movement. Table 29 summarizes some possible CPB disasters, their 
Table 29 Management of accidents on cardiopulmonary bypass

\begin{tabular}{|c|c|c|}
\hline CPB disasters & Management & Prevention \\
\hline \multirow{11}{*}{$\begin{array}{l}\text { Hemorrhage secondary } \\
\text { to a redo sternotomy }\end{array}$} & Hold sternal edges together (assistant) & \multirow{3}{*}{$\begin{array}{l}\text { Preop radiography should identify } \\
\text { cardiac adherence to posterior } \\
\text { sternum }\end{array}$} \\
\hline & Aggressive resuscitation using rapid infuser (anesthesiologist) & \\
\hline & Ice on head & \\
\hline & Groin/neck dissection to isolate vessels & $\begin{array}{l}\text { Prepare groin/neck and isolate } \\
\text { vessels in high risk cases }\end{array}$ \\
\hline & Cool to deep hypothermia & $\begin{array}{l}\text { Prepare CPB circuit lines and be } \\
\text { ready to go in high risk cases }\end{array}$ \\
\hline & Collapse lungs if heart fibrillates (to prevent pulmonary edema) & \multirow{2}{*}{$\begin{array}{l}\text { Blood ready to infuse through rapid } \\
\text { infuser }\end{array}$} \\
\hline & $\begin{array}{l}\text { Continue redo sternotomy with reduced flows (intermittent periods of } \\
\text { circulatory arrest) }\end{array}$ & \\
\hline & Cannulate ascending aorta/right atrium if required & \multirow{4}{*}{$\begin{array}{l}\text { Peripheral cannulation, CPB and } \\
\text { cool in very high-risk cases }\end{array}$} \\
\hline & Complete operation & \\
\hline & Remove peripheral cannulae and repair vessels & \\
\hline & $\begin{array}{l}\text { Suction bypass can also be used following peripheral arterial cannulation } \\
\text { in absence of intracardiac shunt }\end{array}$ & \\
\hline \multirow{3}{*}{$\begin{array}{l}\text { Sudden LV distension } \\
\text { secondary to } \\
\text { undiagnosed PDA/aorto } \\
\text { pulmonary connections }\end{array}$} & Reduce arterial pressure & \multirow{3}{*}{$\begin{array}{l}\text { Preop echocardiogram/ } \\
\text { angiography should identify any } \\
\text { systemic pulmonary connection }\end{array}$} \\
\hline & Vent the left side or readjust vent & \\
\hline & Dissect and ligate PDA & \\
\hline $\begin{array}{l}\text { Aortic dissection (due } \\
\text { to intramural cannula } \\
\text { positioning) }\end{array}$ & Repair aorta if necessary & $\begin{array}{l}\text { Always look at the aorta for any } \\
\text { hematoma while initiating CPB }\end{array}$ \\
\hline \multirow{8}{*}{$\begin{array}{l}\text { Reversed cannulation } \\
\text { (inadvertent connection } \\
\text { of venous cannula to } \\
\text { arterial line and of arterial } \\
\text { cannula to venous line) }\end{array}$} & Diagnosis: low MAP and increased CVP & \multirow{2}{*}{$\begin{array}{l}\text { Always confirm arterial line } \\
\text { pulsatility }\end{array}$} \\
\hline & Flaccid aorta and tense cava by palpation & \\
\hline & AV septal defects can mask this & \multirow{6}{*}{$\begin{array}{l}\text { Trace circuit lines from cannula to } \\
\text { pump }\end{array}$} \\
\hline & Management: & \\
\hline & Discontinue CPB & \\
\hline & Put patient in Trendelenburg position & \\
\hline & Disconnect cannulae, inspect for air and reconnect appropriately & \\
\hline & Reduce cerebral damage using mannitol, steroids and barbiturates & \\
\hline
\end{tabular}

Table 29 (continued) 
Table 29 (continued)

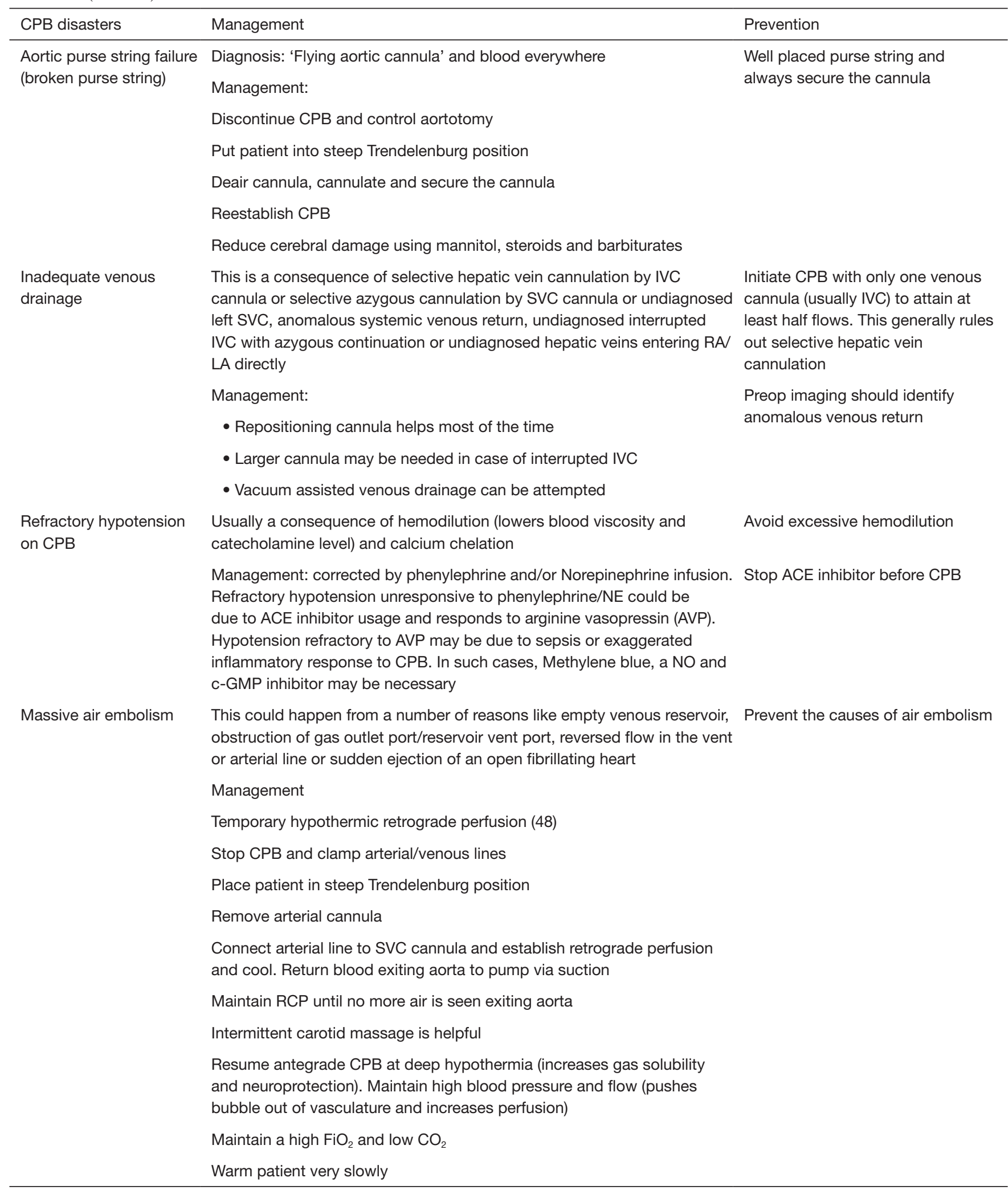

Table 29 (continued) 
Table 29 (continued)

\begin{tabular}{|c|c|c|}
\hline CPB disasters & Management & Prevention \\
\hline \multirow{7}{*}{$\begin{array}{l}\text { Loss of circuit integrity } \\
\text { and equipment failure } \\
\text { (oxygenator/pump/heat } \\
\text { exchanger) }\end{array}$} & If heart is capable of supporting circulation, fill patient and wean off CPB & \multirow{7}{*}{$\begin{array}{l}\text { Perfusionist should check circuit } \\
\text { thoroughly before institution of CPB }\end{array}$} \\
\hline & $\begin{array}{l}\text { If heart is incapable of supporting circulation, cool to deep hypothermia in } \\
\text { anticipation of circulatory arrest }\end{array}$ & \\
\hline & Place ice on head & \\
\hline & Terminate CPB & \\
\hline & Replace the components & \\
\hline & Remove air & \\
\hline & Reestablish CPB & \\
\hline
\end{tabular}

LV, left ventricle; CPB, cardiopulmonary bypass; IVC, inferior vena cava; SVC, superior vena cava; RA, right atrium; LA, left atrium.

management and prevention.

One of the most common reasons for disasters in the operating room is lack of proper communication between the members of the team. Studies have shown that effective communication contributes highly to cardiac team success $(49,50)$.

In addition to the above mentioned accidents, there can be other unusual problems in CPB (51).

There are also specific situations with unique challenges to $\mathrm{CPB}$ which the surgeon should be aware of. They are:

(I) Increased collateral return: usually in preexisting cyanosis of long duration.

(i) Large or more than one left heart vent may be required;

(ii) Hypothermia: operating in dependent regions difficult because of the flooding of blood. So one may be forced to use lower flows. Hypothermia permits lower flows. Continuous monitoring of venous saturations imperative;

(iii) Deairing easier but quicker. Beware of heart distension;

(iv) Hypothermia also provides myocardial protection in face of increased return to heart and wash out of cardioplegia.

(II) In Jehovah's witness, consider the following:

(i) A lower threshold for elective groin dissection/ cannulation in redo cases;

(ii) Cell saver;

(iii) Hemodilution;

(iv) Venous autologous perfusion (VAP)/retrograde aortic perfusion (RAP).

\section{Conclusions}

There is no doubt that there will continue to be progress to make CPB easier and safer for children in the future. However, the principles for conducting a safe $\mathrm{CPB}$ will continue to be the same. A firm hold over these principles of $\mathrm{CPB}$ is imperative for good surgical outcomes.

\section{Acknowledgments}

Funding: None.

\section{Footnote}

Provenance and Peer Review: This article was commissioned by the Guest Editor (Raghav A. Murthy) for the series "Management of Congenital Heart Disease" published in Fournal of Thoracic Disease. The article was sent for external peer review organized by the Guest Editor and the editorial office.

Conflicts of Interest: The series "Management of Congenital Heart Disease" was commissioned by the editorial office without any funding or sponsorship. The author has no other conflicts of interest to declare.

Ethical Statement: The author is accountable for all aspects of the work in ensuring that questions related to the accuracy or integrity of any part of the work are appropriately investigated and resolved.

Open Access Statement: This is an Open Access article 
distributed in accordance with the Creative Commons Attribution-NonCommercial-NoDerivs 4.0 International License (CC BY-NC-ND 4.0), which permits the noncommercial replication and distribution of the article with the strict proviso that no changes or edits are made and the original work is properly cited (including links to both the formal publication through the relevant DOI and the license). See: https://creativecommons.org/licenses/by-nc-nd/4.0/.

\section{References}

1. Wahr JA, Prager RL, Abernathy JH 3rd, et al. Patient safety in the cardiac operating room: human factors and teamwork: a scientific statement from the American Heart Association. Circulation 2013;128:1139-69.

2. Gibbon $\mathrm{JH} \mathrm{Jr}$, Application of a mechanical heart and lung apparatus to cardiac surgery. Minn Med 1954;37:171-85; passim.

3. Stoney WS, Alford WC Jr, Burrus GR, et al. Air embolism and other accidents using pump oxygenators. Ann Thorac Surg 1980;29:336-40.

4. Limperopoulos C, Majnemer A, Shevell MI, et al. Predictors of developmental disabilities after open heart surgery in young children with congenital heart defects. J Pediatr 2002;141:51-8.

5. Mejak BL, Stammerss A, Rauch E, et al. A retrospective study on perfusion incidents and safety devices. Perfusion 2000;15:51-61.

6. American Society of Extracorporeal technology. Guidelines for perfusion practice. Perfusion Life 1995;12:20-2.

7. Baile EM, Ling H, Heyworth JR, et al. Bronchopulmonary anastomotic and noncoronary collateral blood flow in humans during cardiopulmonary bypass. Chest 1985;87:749-54.

8. Chai PJ. Myocardial protection and preservation for neonates and infants. In: Gravlee GP, Davis RF, Stammers AH, et al. editor. Cardiopulmonary Bypass: Principles and Practice. 3rd edition. Philadelphia: Lippincott Williams and Wilkins, 2008:700-9.

9. Hessel EA. Circuitry and cannulation Techniques. In: Gravlee GP, Davis RF, Stammers AH, et al. editor. Cardiopulmonary Bypass: Principles and Practice. 3rd edition. Philadelphia: Lippincott Williams and Wilkins, 2008:63-113.

10. Jonas RA. Anomalies of pulmonary veins. In: Jonas RA, Dodson R, DiNardo J, et al. editor. Comprehensive Surgical Management of Congenital Heart Disease. 1st edition. London: Hodder Arnold Publication, 2004:402-12.

11. Kouchoukos NT, Doty DB, Hanley FL, et al. Hypothermia, circulatory arrest and cardiopulmonary bypass. In: Kouchoukos N, Blackstone E, Hanley F, et al. editor. Kirklin/Barratt-Boyes Cardiac surgery. 4th edition. Philadelphia: Elsivier, 2003:66-130.

12. Demmy TL, Biddle JS, Bennett LE, et al. Organ preservation solutions in heart transplantation--patterns of usage and related survival. Transplantation 1997;63:262-9.

13. McLean TR, Jones JW, Svensson LG, et al. Selective topical cooling for myocardial protection. Cardiovasc Surg 1993;1:176-81.

14. Allen BS, Winkelmann JW, Hanafy H, et al. Retrograde cardioplegia does not adequately perfuse the right ventricle. J Thorac Cardiovasc Surg 1995;109:1116-24; discussion 1124-6.

15. Winkelmann J, Aronson S, Young CJ, et al. Retrogradedelivered cardioplegia is not distributed equally to the right ventricular free wall and septum. J Cardiothorac Vasc Anesth 1995;9:135-9.

16. Rosenkranz ER, Okamoto F, Buckberg GD, et al. Safety of prolonged aortic clamping with blood cardioplegia. II. Glutamate enrichment in energy-depleted hearts. J Thorac Cardiovasc Surg 1984;88:402-10.

17. Tixier D, Matheis G, Buckberg GD, et al. Donor hearts with impaired hemodynamics. Benefit of warm substrateenriched blood cardioplegic solution for induction of cardioplegia during cardiac harvesting. J Thorac Cardiovasc Surg 1991;102:207-13; discussion 213-4.

18. Akins CW, Carroll DL. Event-free survival following nonemergency myocardial revascularization during hypothermic fibrillatory arrest. Ann Thorac Surg 1987;43:628-33.

19. Jessen ME, Abd-Elfattah AS, Wechsler AS. Neonatal myocardial oxygen consumption during ventricular fibrillation, hypothermia, and potassium arrest. Ann Thorac Surg 1996;61:82-7.

20. Archie JP Jr. Intramyocardial pressure: effect of preload on transmural distribution of systolic coronary blood flow. Am J Cardiol 1975;35:904-11.

21. Babaroglu S, Yay K, Parlar AI, et al. Beating heart versus conventional mitral valve surgery. Interact Cardiovasc Thorac Surg 2011;12:441-7.

22. Magovern JA, Pae WE Jr, Waldhausen JA. Protection of the immature myocardium. An experimental evaluation of topical cooling, single-dose, and multiple-dose administration of St. Thomas' Hospital cardioplegic solution. J Thorac Cardiovasc Surg 1988;96:408-13.

23. Baker JE, Boerboom LE, Olinger GN. Cardioplegia-induced damage to ischemic immature myocardium is independent of oxygen availability. Ann Thorac Surg 1990;50:934-9.

24. Kouchoukos NT, Doty DB, Hanley FL, et al. Myocardial 
Management during cardiac surgery with cardiopulmonary bypass. In: Kouchoukos N, Blackstone E, Hanley F, et al. editor. Kirklin/Barratt-Boyes Cardiac surgery. 4th edition. Philadelphia: Elsivier, 2003:131-62.

25. Jonas RA. Myocardial protection. In: Jonas RA, Dodson R, DiNardo J, et al. editor. Comprehensive Surgical Management of Congenital Heart Disease. 1st edition. London: Hodder Arnold Publication, 2004:175-84.

26. Bennett EV Jr, Fewel JG, Grover FL, et al. Myocardial preservation: effect of venous drainage. Ann Thorac Surg 1983;36:132-42.

27. Rosenfeldt FL, Watson DA. Interference with local myocardial cooling by heat gain during aortic crossclamping. Ann Thorac Surg 1979;27:13-6.

28. Shahian DM. Retrograde coronary sinus cardioplegia in the presence of persistent left superior vena cava. Ann Thorac Surg 1992;54:1214-5.

29. Santoscoy R, Walters HL, Ross RD, et al. Coronary sinus ostial atresia with persistent left superior vena cava. Ann Thorac Surg 1996;61:879-82.

30. Gregoretti S. Suction-induced hemolysis at various vacuum pressures: implications for intraoperative blood salvage. Transfusion 1996;36:57-60.

31. Wright G, Sanderson JM. Cellular aggregation and trauma in cardiotomy suction systems. Thorax 1979;34:621-8.

32. Brooker RF, Brown WR, Moody DM, et al. Cardiotomy suction: a major source of brain lipid emboli during cardiopulmonary bypass. Ann Thorac Surg 1998;65:1651-5.

33. Hessel EA. Bypass techniques for descending thoracic aortic surgery. Semin Cardiothorac Vasc Anesth 2001;5:293-320.

34. Ho KM, Tan JA. Benefits and risks of maintaining normothermia during cardiopulmonary bypass in adult cardiac surgery: a systematic review. Cardiovasc Ther 2011;29:260-79.

35. Cook DJ. Changing temperature management for cardiopulmonary bypass. Anesth Analg 1999;88:1254-71.

36. Tönz M, Mihaljevic T, von Segesser LK, et al. Normothermia versus hypothermia during cardiopulmonary bypass: a randomized, controlled trial. Ann Thorac Surg 1995;59:137-43.

37. Mills GH, Khan ZP, Moxham J, et al. Effects of temperature on phrenic nerve and diaphragmatic function during cardiac surgery. Br J Anaesth 1997;79:726-32.

38. Insler SR, Sessler DI. Perioperative thermoregulation and temperature monitoring. Anesthesiol Clin 2006;24:823-37.

39. Robbins RC, Balaban RS, Swain JA. Intermittent hypothermic asanguineous cerebral perfusion (cerebroplegia) protects the brain during prolonged circulatory arrest. A phosphorus 31 nuclear magnetic resonance study. J Thorac Cardiovasc Surg 1990;99:878-84.

40. Langley SM, Chai PJ, Miller SE, et al. Intermittent perfusion protects the brain during deep hypothermic circulatory arrest. Ann Thorac Surg 1999;68:4-12; discussion 12-3.

41. Furuya H, Suzuki T, Okumura F, et al. Detection of air embolism by transesophageal echocardiography. Anesthesiology 1983;58:124-9.

42. Roger L, Royster SJT, Davis RF. Termination of cardiopulmonary bypass. In: Gravlee GP, Davis RF, Stammers AH, et al. editor. Cardiopulmonary Bypass: Principles and Practice. 3rd edition. Philadelphia: Lippincott Williams and Wilkins, 2008:614-31.

43. Ungerleider RM. The use of intraoperative echocardiography with Doppler color flow imaging in the repair of congenital heart defects. Echocardiography 1990;7:289-304.

44. Ungerleider RM, Kisslo JA, Greeley WJ, et al. Intraoperative echocardiography during congenital heart operations: experience from 1,000 cases. Ann Thorac Surg 1995;60:S539-42.

45. Elliott MJ. Ultrafiltration and modified ultrafiltration in pediatric open heart operations. Ann Thorac Surg 1993;56:1518-22.

46. Bando K, Vijay P, Turrentine MW, et al. Dilutional and modified ultrafiltration reduces pulmonary hypertension after operations for congenital heart disease: a prospective randomized study. J Thorac Cardiovasc Surg 1998;115:517-25; discussion 525-7.

47. Jenkins OF, Morris R, Simpson JM. Australasian perfusion incident survey. Perfusion 1997;12:279-88.

48. Mills NL, Ochsner JL. Massive air embolism during cardiopulmonary bypass. Causes, prevention, and management. J Thorac Cardiovasc Surg 1980;80:708-17.

49. Edmondson AC, Bohmer RMJ, Pisano GP. Speeding up team learning. Harv Bus Rev 2001:125-32.

50. Awad SS, Fagan SP, Bellows C, et al. Bridging the communication gap in the operating room with medical team training. Am J Surg 2005;190:770-4.

51. Segesser LK. Unusual problems in cardiopulmonary bypass. In: Gravlee GP, Davis RF, Stammers AH, et al. editor. Cardiopulmonary Bypass: Principles and Practice. 3rd edition. Philadelphia: Lippincott Williams and Wilkins, 2008:608-13.

Cite this article as: Kumar TKS. Practical conduct of open heart procedures for congenital heart lesions. J Thorac Dis 2020;12(3):1235-1259. doi: 10.21037/jtd.2019.11.80 